"ratio can exist only between quantities of the same kind." When mathematicians employ the figures of 4 to 3 in the scale of $\mathrm{C}$, the interval they really obtain is from $\mathrm{C}$ down to $\mathrm{G}$ (not from $\mathrm{F}$ down to $\mathrm{C}$, as they have supposed), and when 5 to 3 , they have the major Sixth from $\mathrm{E}$ down to $\mathrm{G}$, and not the one from $\mathrm{A}$ down to $\mathrm{C}$.

Music is a much more simple science than most men suppose. All that a mathematician requires is a set of harmonic scales, with powers of 2 and 3, before him. The scales include all ratios, and all consonances with their proportions of accompanying dissonances. They are scales of aliquot parts, and those aliquot parts are the corresponding multiples of vibrations. Time spent upon calculating temperainent is but thrown away, because no mathematician's figures will be adopted in practice. Practical musicians will continue to tune by listening to the beats, as they have ever done, and perhaps all other musicians before them. The recommendation to eschew temperament may be even worthy of consideration in another point of view. Mathematicians have not given sufficient attention to the musical side of the question. Have we not, of late years, heard much of proposals to divide the octave into "twelve equal semitones"? Are we to imagine that this is a mathematician's idea of "equal temperament"? If music were but geometry, it would be an admirable arrangement: twelve equal semitones, like twelve equal inches in a foot. But, unfortunately, a musical scale is the very reverse of a geometrical one, and there are no two intervals alike in it. As it rises, the dimensions become less at every step, in ratio and in length. For instance, the ratio of $C$ to $C$ sharp is 16 to 17 , that of $G$ to $\mathrm{G} \operatorname{sharp}$ ( $\mathrm{G}$ being the half-way in point of vibrations) is 24 to 25 , and from $\mathrm{B}$ to octave $\mathrm{C}$ is 30 to 32 , but only because we omit 3 sharp, otherwise it would be $3 \mathrm{I}$ to 32 . Fancy two such extremes "tempered" to the middle note! Only one of the twelve would fit into a musical scale, and there would be eleven discordant semitones out of the twelve. The discord would not be confined to one key only, but would be the same in every liey. The so-called "diatonic semitones" are really tones. $\mathrm{E}$ is the seventh to F, which requires $F$ as a bass, and $B$ is the seventh to $\mathrm{C}$ in the scale of $\mathrm{C}$. Are these to be changed into chromatic semitones?

The diminished attraction of music, some persons even disliking it, is mainly, if not wholly due to tempered tones. The first point to be considered by mathematicians who termper scales is the meaning of the two words, "consonance" and "dissonance." The charm of music depends upon "coincident," and "non-coincident" vibration.

In justice to Col. A. R. Clarke, let me add that I find only the first error to be his own, and am still disposed to attribute it to oversight in referring to a wrong scale. All the others are after precedent, and every source might be pointed out, although he is disposed chivalrously enough to defend those upon whom he relied. My excuse for writing at all is that NATURE is a purely scientific journal, and that $x$ share with others an earnest wish to uphold it as a fair representative of English thought. Articles such as those of Col. Clarke and my own would be distasteful to any but scientific readers. As to the "comma of Pythagoras," it is not worth discussing. In spite of his chivalry, Col. Clarke knows as well as I do, that such an array of figures, representing vibrations, as 524,288 , cannot arise in less than nineteen octaves.

Strafford Lodge, Oatlands Park, Surrey

\section{The Nebula of Orion}

IN NATURE, vol. xv. p. 20l, in an account of the American Cambridge Observatory, it is stated that the nebula of Orion had not shown the slightest trace of resolvability under Lord Rosse's 3 -feet reflector.

The authority for this statement is, I suppose, Nichol's "Thoughts on the System of the World," where, p. 52, it is said that in $1844-5$, the 3 -feet did not contain the vestige of a star in the nebula.

On the occasion there referred to the speculum must have been in bad order, for the resolution of parts of the nebula is quite within the reach of the instrument in its normal condition. In proof of this I may refer to Lord Oxmantown's paper on the Nebula of Orion, Phil. Trans., 186r, and to an extract from'my own note-books of an earlier date, February, 1848 :- " With the 3 -feet saw the nebula of Orion resolved as far up as the little bay and $\mathrm{C}_{\mathrm{I}}$ Orionis--powers $35 \mathrm{I}$ and 320 -best with the latter which is a single lens."
I may add that Nichol also states, p. 55 , that he had received from Lord Rosse, March 19, 1846 intelligence "that all about the trapezium is a mass of stars (in the six feet); the rest of the nebula also abounding with stars, and exhibiting the characteristics of resolvability strongly marked."
Observatory, Armagh, January 19
T. R. ROUINSON

\section{Basking Shark}

My notice of Prof. Steenstrup's paper was written in the autumn of 1875 , to accompany an electrotype of the woodcut in that paper of the baleen-like fringes of the basking shark, sent to me for NATURE from Copenhagen.

At the time I was quite ignorant that my friend and former master, Dr. Allman, had written on the subject, nor could the keenest bibllographer have known much of the contents of his memoir, as the only reference to it in the Fourth Annual Report of the Dublin Natural History Society for $x 8_{4} \mathrm{I}-42$, is "Two [papers] have been read on Icthyology; that on the basking shark (Selachus maximus) by Mr. Allman, caused him to notice the value of the fisheries of our southern coasts, abounding in large fishes and cetacea, whose capture would prove highly profitable to our fishermen from the quantity of oil they would yield." In June, 1876 , on the arrival of the specimen in Dublin from Bofin, I had a woodcut made of a branchial arch with the fringe attached, and added a brief account of the specimen now in the Dublin Museum. About that time Dr. Allman fold me that notes of his paper had been published in the Saunders' News Letter, but that he had forgotten the date. Guided by the notice in the Dublin Natural History Society's Report, I searched the files of that paper for the years I $84 \mathrm{I}$ and 1842 without success, but I fully purposed to mention what Dr. Alllman had told me, from memory, of his researches, when I should get a proof of my manuscript. Unfortunately, from press of matter, my notes were not published until many weeks after they were sent, and the proof reached me during long vacation, when I completely forgot to do as $I$ had intended. I regret this exceedingly, and hope Dr. Allman will accept my apology. I cannot, how. ever regret, that it has induced Dr. Allman to publish an abstract of his paper (NATURE, vol. xiv. p. 368), and perhaps he may still further furnish us with the date of its original publication.

In answer to the note of Prof. Enrico Giglioli, which bas called my attention again to this subject, I have simply to state that inding no notice in the Zoological Records for 1873 or for 1874 (this latter published May, I876) of any papers on Selache, I concluded, as it now appears wrongly, that rothing had been written during these years on the subject. This was my misfortune, perhaps my fault; but regarding Italy as the mother country of all the sciences, being well aware of the advances she has made in biological researches during the last twenty years, and having gone each year, while one of the zoological recorders, to Florence to work out the Italian literature of the preceding year, I cannot accuse myself of any intentional neglect of the labours of Italian biologists. It is to be hoped that Prof. Giglioli will favour us with an abstract of Prof. Pavesi's memoir, especially of the reasons that induce Prof. Pavesi to assert that our Bofin shark is $S$. rosirata and not $S$. maxima, for to me it appears that our seas may possess both these species.

It may also be mentioned that no reference to Prof. Pavesi's memoir will be found in the account of the Pelerin appended to Prof. Luitken's "Fishes of Greenland," prepared for the use of the British North Polar Expedition, 1875.

\section{E. Percival Wright}

\section{Sense of Hearing in Insects and Birds. "Towering" of Birds}

I Alr glad to learn from Mr. M'Lachlan that stridulation is known to occur in several species of Lepidoptera; for this shows that the sense of hearing in these insects is probably of general occurrence. With regard to the sense of hearing in birds, I did not say in my previous letter that thrushes, \&c., were guided to their food exclusively by this sense; indeed it would be a very anomalous thing if animals which possess so keen a sense of sight are not in the habit of using it, as Mr. McLachlan suggests, in any profitable way they can. But that thrushes trust very largely to their sense of hearing in their search for foodespecially in certain conditions of the ground-no one, I think, who has observed the process can doubt. The bird runs rapidly some twelve to twenty feet in a straight line; it then stops 